\title{
Historieta y mitos políticos: la relectura oficial de El eternauta en la Argentina democrática
}

\author{
(a) \\ Laura Cristina Fernández** \\ Sebastian Gago***
}

Recibido: 20 de febrero de 2012 Aprobado: 27 de marzo de 2012

\begin{abstract}
Resumen
Este trabajo se propone analizar la vinculación más reciente entre mitos políticos e historietas en la Argentina de la posdictadura, indagando sobre la construcción de modelos de sociedad y de conflicto político presentes en los discursos de este tipo de productos culturales. Para ello, consideramos algunas variables del anclaje de la historieta en la cultura y la política de una sociedad.

Investigamos los usos de iconos y productos culturales por parte de agentes discursivos ligados directa o indirectamente con el Estado-Gobierno, como partidos políticos, movimientos sociales y culturales, y empresas editoriales, algunas de las cuales están dedicadas a la comunicación. La inserción, a fines de 2010, de la simbología y la iconografía del personaje de historieta El Eternauta, como un componente de la interpelación discursiva del kirchnerismo, se relaciona con las prácticas de formación de identidades políticas y culturales en el contexto de las luchas por imponer una visión del mundo social.
\end{abstract}

Asimismo, reconstruimos y describimos factores del contexto social e histórico que, en tanto condiciones de posibilidad discursiva, resultan claves para comprender el uso de la historieta como herramienta política.

Palabras clave: discursos, sentido, mitos, historietas, Kirchner.

\footnotetext{
El proyecto es financiado por la Secretaría de Ciencia y Tecnología de la UNC. Los subproyectos de los cuales se origina este artículo son la tesis doctoral de Laura C. Fernández Oesterheld como mito fundante. Instauración y manifestaciones de una poética pedagógico-política en el campo de la historieta local desde 1975 hasta la posdictadura; y la tesis doctoral de Sebastian Gago Sesenta años de lecturas de la obra de Héctor Germán Oesterheld. Construcción de sentido, por distintas cohortes de lectores, en el consumo de historietas de Héctor Germán Oesterheld: de 1950 al presente. Ambos trabajos tienen en común el estudio y el relevamiento de las lecturas y la herencia del guionista Héctor Oesterheld, en tanto autor canónico, en la producción de autores de historietas posteriores. La línea de investigación es el Estudio Científico y Crítico sobre la Historieta.

** Actualmente se desempeña en la Facultad de Ciencias Políticas y Sociales de la Universidad Nacional de Cuyo. Mendoza, Argentina. Correo electrónico: ninaefe@yahoo.com.ar

*** Licenciado en Comunicación Social de la Universidad Nacional de Córdoba (UNC), Argentina. Doctorando en Estudios Sociales de América Latina, por el Centro de Estudios Avanzados, UNC. Forma parte del equipo de Investigación "Estudio y Crítica de la Historieta Argentina" con sede en la Escuela de Ciencias de la Información, Universidad Nacional de Córdoba (UNC), Argentina en el marco del cual investiga científicamente la recepción de historietas en Argentina. Correo electrónico: shgago@gmail.com
} 


\title{
Comics and Political Myths: Official Re-Reading of "El Eternauta" during Democracy in Argentina
}

\begin{abstract}
This article proposes the analysis of the most recent association between political myths and comics in Argentina after dictatorship, by inquiring about the erection of society and political conflict models present in speeches from this kind of cultural products. For this reason, some variables of the comic inclusion in culture and politics of a society have been considered.

A research was conducted on the use of icons and cultural products by discursive agents directly or indirectly linked to the State-Government, such as political parties, social and cultural movements, and publishing companies, some of which are devoted to communication. Late in 2010, insertion of symbology and iconography of the main character of "El Eternauta," as an element of the discursive questioning of "Kirchnerism," is associated to a practice intended to form political and cultural identities in a context of struggles intended to impose a vision of the social world.

Likewise, factors of the social and historical context have been reconstructed and described that, as conditions of discourse possibility, become a key factor for understanding the use of comics as a political tool.
\end{abstract}

Key words: Speeches; sense; myths; comics; Kirchner. 


\section{Introducción}

Nuestro análisis apunta a encontrar continuidades y discontinuidades y, a partir de ellas, usos de ciertas potencialidades inscritas en el espacio social y político de la Argentina. La inserción, a partir de septiembre del año 2010, de la simbología y la iconografía del personaje de historieta El Eternauta como un componente de la interpelación discursiva del peronismo en el poder, constituye un proceso de doble faz, inscrito en los cruces arte/política en las posdictaduras de la región. Tal proceso se relaciona con las prácticas de formación de identidades políticas y culturales en el contexto de las luchas por imponer una visión del mundo social.

Consideramos a la historieta una práctica comunicacional, y como tal, produce sentido, es decir, modelos de/sobre la realidad que se construyen y ponen en circulación en distintos tipos de discursos (Bourdieu, 1995; Verón, 1993). En tanto práctica social y comunicacional y, al mismo tiempo, discurso producido en ciertas condiciones sociales, la historieta juega un rol social como constructora de sentido. Si decimos que todo discurso social implica una construcción de un modelo de realidad, el discurso político es aquel discurso cuyo interés se dirige a ejercer efecto político, intervenir en las luchas por la definición legítima de un modelo de organización o de dirección de la sociedad (Bourdieu, 1990). La historieta, en tanto discurso eventualmente portador de un significado político -en ocasiones más, otras veces menos explícitamente-, puede constituirse en una herramienta comunicacional que disputa sentidos, retomando valores sociales ${ }^{1}$.

Para que el discurso político tenga credibilidad o eficacia, deben existir agentes con disposiciones a creer y valorar el discurso (Bourdieu,

1 En El Eternauta primera parte, por ejemplo, el modelo social construido por el autor está regido por los valores de solidaridad, cooperativismo, lealtad al grupo de pertenencia, horizontalidad en el proceso de toma de decisiones, el valor de la vida como fin y no como medio, entre otros.
1990). Cuando el productor lingüístico niega, dramatiza, eufemiza o desconoce su posición, esta tiene posibilidades de aparecer transfigurada en poder social. Estas prácticas de dramatización, negación y/o eufemización se ajustan a la construcción de mito: un tipo de discurso, de naturaleza ideológica, que muestra lo que oculta y/o distorsiona (Barthes, 1999). Según Barthes, lo que define al mito no es el objeto de su mensaje, sino la forma en que tal mensaje es dado: el mito es el reemplazo del sentido de una forma, por lo cual es preciso que exista una historia previa a la cual el mito pueda remitir, operación que es clara en la construcción heroica de Kirchner, como veremos más adelante. Verón y Sigal (1986) afirman que

... todo discurso político contiene, como una de sus dimensiones fundamentales, la recuperación de la historia. Cada posición política reconstruye la historia a su manera, con el fin de enraizar el movimiento social o partido en la lógica de un desarrollo y mostrar su "necesidad". La historia aparece, entonces, como metáfora del presente (p.182).

El mito del peronismo radica en su autoconcepción como movimiento político y social portador de una "visión de futuro" que lo destaca por sobre la masa o los demás referentes políticos y lo coloca en el rol de dirigir a la sociedad. Además, se procura el monopolio de la definición legítima de lo político y de aquello por lo que se debe luchar en la política: los intereses "nacionales" y "populares". Tal construcción sustenta al peronismo, por un lado, como representante de los intereses del "Pueblo" y de la "Nación", categorías identificables e intercambiables entre sí dentro de esta retórica -en tanto portavoz de ambas-; y, por otro lado, en un movimiento de resistencia frente a quien/es son considerados parte de la "anti-Nación" o el "anti-Pueblo" (Cf. Sánchez y Olivares, 2010). Estos Otros/antagonistas, dependiendo del contexto sociohistórico y político, han sido construidos bajo diversas entidades del imaginario: "oligarquía", "imperialismo", "gorilas", "la derecha". Y las estrategias de producción de la 
eficacia simbólica propias del mito se plasman en prácticas discursivas que son tradicionales de dirigentes políticos reconocidos o auto-identificados como "progresistas" u "obreristas". Verbigracia, la interpelación al público oyente mediante la categoría "compañeros". Esta y otras estrategias de negación del poder apuestan a monopolizar la legitimidad del uso de "Pueblo" y de lo "popular", pues ello "[...] permite a aquellos que pueden reivindicar una forma de proximidad con los dominados colocarse como poseedores de una suerte de derecho de precedencia sobre el pueblo, y, por ende, de una misión exclusiva" (Bourdieu, 1987, p.154). A su vez, el uso del vocablo "Pueblo" permite al dirigente distinguirse de sus adversarios y enmascarar la relación de dominación política que se evidencia, en el mismo discurso, en el ejercicio del rol de portavoz.

En el caso estudiado, observamos un modelo de construcción heroica mítica que exacerba características "guerreras" del héroe y mantiene una estructura de relato de Cotidianeidad Negativa (CN) (Roig, 1984), pues modeliza un héroe que se rebela contra una realidad que lo oprime o bien halla injusta, asumiendo el rol de portavoz de un grupo social. El héroe asume la misión de desvelar y/o reparar el daño social, político o cultural, dentro de un relato preconcebido para exceder el esquema de héroe, convirtiendo al personaje en mito. Para ello, es fundamental reconstruir retrospectivamente un pasado ajustado a las necesidades del presente, para delimitar y dirigir el sentido, siempre abierto, tanto del presente como del futuro (Bourdieu, 1987).

Volviendo a Barthes (1999), el mito implica una apropiación de otros lenguajes, siendo su principal objetivo naturalizar el discurso que plantea. No obstante, se trata de una construcción histórica, un "habla", que poco tiene de "puro" o esencial. Por ejemplo, en el caso de la mitificación de un mito político anterior, lo que llevaría a producir un "mito artificial" que desataría una cadena semiológica; o bien podría tratarse de un modelo de mito heroico "natural", es decir, una construcción mítica autosuficiente y autorreferencial. Los procesos de apropiación se relacionan con el uso y las prácticas alrededor de los objetos culturales dentro de cierto contexto histórico. Los textos adquieren nueva vida cuando son recuperados no solo en su significación sino en su práctica social (Chartier, 2002).

\section{Metodología}

Metodológicamente, nos posicionamos en el análisis sociológico, socio-discursivo y semiótico del sentido del empleo de recursos textuales e icónicos procedentes de la historieta y de otras manifestaciones del campo cultural, dentro de una serie de discursos del oficialismo político en Argentina. Además, se realiza una reconstrucción y descripción de una serie de factores del contexto social e histórico que, en tanto condiciones de posibilidad discursiva, resultan claves para comprender el uso de la historieta como herramienta militante.

Los aportes conceptuales desde los cuales emprendemos el mismo son la teoría de la cultura de Pierre Bourdieu y algunas herramientas tanto de la semiótica como del análisis crítico del discurso social (Verón, 1993; Jitrik, 1995; Barthés, 1999).

\section{Resultados}

\section{Reseña de la historieta El Eternauta y de su trayectoria de canonización}

El Eternauta es una historieta de ciencia ficción creada por Héctor Oesterheld, y dibujada por Francisco Solano López durante 1957-1959 para editorial Frontera. En ella se narra una invasión extraterrestre en Buenos Aires, liderada por los poderosos "Ellos", frente a la cual los protagonistas (Juan Salvo, su familia y amigos) intentan sobrevivir. Este primer relato es reescrito en 1969, con dibujos de Alberto Breccia, y publicado en revista "Gente" de Editorial Atlántida. La rever- 
sión presentaba un argumento marcado por el discurso político de izquierda y un estilo gráfico experimental, razones por las cuales esta publicación de la historieta es interrumpida. Durante 1976, comienza a publicarse una segunda parte de El Eternauta, otra vez con dibujos de Solano López, para revista "Skorpio" de Ediciones Récord. Oesterheld ya es agente de prensa de la organización Montoneros y trabaja en la clandestinidad: el discurso es enfático, a veces doctrinario, de lucha militar revolucionaria. Es aquí donde personaje y autor son amalgamados por el imaginario posdictatorial como un modelo de héroe rebelde/militante de izquierda, fundidos por la resistencia y el sacrificio: el Eternauta pierde a su familia, al igual que Oesterheld, quien es también desaparecido en 1977 y, según los testimonios recuperados en el informe de la CONADEP, posiblemente ejecutado el mismo año que se termina de publicar la segunda parte de su historieta (1978).

Es vasta la trayectoria de consagración cultural de El Eternauta, que se inicia en los años sesenta, desde fuera del campo de la historieta argentina, más precisamente del mercado europeo y luego del campo artístico e intelectual argentino -sobre todo a partir de la Bienal Internacional de la Historieta organizada por el Instituto Di Tella, en 1968-. La revalorización y relectura de la obra de Oesterheld incluyó en los años setenta a un grupo de intelectuales que posicionaron al autor como el canon de la historieta local (entre ellos, Carlos Trillo y Oscar Masotta). Estos hechos abonarían el terreno para la posterior canonización ${ }^{2}$ de Oesterheld y de su obra prima. La misma fue iniciada desde sectores del campo de la produc-

2 Canonización es el proceso de institución por el cual, dentro de ciertos límites y clasificaciones que son producto de luchas (Cf. Bourdieu, 1995:113 y 333), un artista o una obra accede al valor estético y además se torna un modelo legítimo reconocido por el conjunto del campo de producción y consumo donde se inscribe. El canon genera efectos en los campos de producción donde las legitimidades se fundan según el principio de la autonomía, y donde la ley específica del cambio es la dialéctica de la distinción (Ibíd., 235). La naturalización de la percepción del estatus de "canónico" de una obra o artista hará que el mismo sea visto o valorado como merecedor de ese estatus o plus de capital simbólico. ción cultural a partir de la transición democrática del país, y fue coetánea con la reconstrucción de la figura pública del autor. La imagen del Oesterheld militante y desaparecido comenzaría recién a conocerse y construirse públicamente después de la derrota argentina en la guerra de Malvinas. Estos elementos son claves para comprender la relectura de El Eternauta en clave de resistencia al poder, y como una premonición de la dictadura que gobernó el país entre 1976 y 1983.

La intervención del Estado nacional, en el último lustro, constituye una importante instancia de canonización de la obra en tanto producto del campo de la historieta. La inclusión de esta historieta, desde 2007, como material de lectura en el sistema de enseñanza media estatal de Argentina ${ }^{3}$, constituye un elemento novedoso en la trayectoria histórica de la recepción de El Eternauta, y que promueve nuevos tipos de apropiación y de construcción de sentido. Pensamos que el Gobierno nacional, al usar la iconografía y la simbología de El Eternauta en el marco de la narrativa mítica del "Eternéstor", practica una apropiación del capital simbólico y político de la obra de Oesterheld.

No obstante, en los últimos años han sido numerosas las apropiaciones, significaciones y reproducciones de El Eternauta en particular, en diversos ámbitos sociales que van más allá del oficialismo político. Por ejemplo, hay bibliotecas populares, centros culturales y agrupaciones sociales y políticas con el nombre del autor o de su historieta; libros -algunos académicos y otros no- y textos periodísticos que analizan y critican la obra y trayectoria del autor; prólogos de reediciones, muestras y homenajes; adaptaciones en radioteatros y en teatro; documentales cinematográficos; foros de discusión y archivos históricos en Internet; programas de televisión que han dedicado varios envíos a rescatar el trabajo del

3 Pensamos en el papel que el Estado ha tenido, en diferentes contextos históricos y geográficos, en la canonización de obras ya consagradas, es decir, la reconsagración de lo consagrado (Cf. Bourdieu, 1995). 
autor; las ya mencionadas actividades escolares de lectura y análisis de El Eternauta; entre otras manifestaciones culturales. Estas apropiaciones y reproducciones han afectado, en formas variables, el conocimiento y reconocimiento de esta historieta.

\section{Análisis}

El Eternauta se ha tornado un icono cultural y político, que a lo largo de distintas etapas de la historia argentina ha sido vinculado a ciertos contextos sociopolíticos. Actualmente, esta historieta está asociada a una parte del peronismo -aunque no lo esté en forma exclusiva-, asociación que se relaciona con la politización de la obra de Oesterheld desde fines de los años sesenta. Fue Oesterheld el primero en utilizar, a veces preconcebidamente, a sus historietas como herramienta militante. Al respecto, existen contradicciones entre los distintos modelos de sociedad construidos por el autor en sus distintas partes y versiones, cuestión que hemos descrito anteriormente.

Uno de los puntos a tener en cuenta en el análisis del universo del "Eternéstor", es el contexto histórico-político de producción y circulación de la serie de mensajes que lo conforman. Podemos situar al acto de las "juventudes kirchneristas" en el estadio Luna Park, realizado el 14 de setiembre de 2010, como su punto central. En la campaña de promoción de este evento político partidario (cuyo eslogan fue "Néstor le habla a la juventud, la juventud le habla a Néstor") fueron, primero, lanzados tres tipos de afiches: 1 - con la estética de las serigrafias pop de Andy Warhol, utilizando como motivo el rostro de Kirchner; 2- un diseño que apela a la imaginería peronista tradicional, con colores blanco, celeste y negro; y 3- con la mítica -y mitificada- iconografía de la historieta El Eternauta, imagen bautizada por algunos medios de comunicación como "Eternéstor" o "Nestornauta". Luego de que, un par de días antes del acto, se descartara la intervención discursiva del expresidente debido a problemas de salud y se decidiera que Cristina Fernández fuera la oradora principal, se lanzaron nuevos afiches a las calles y flyers vía web: uno de ellos llevaba una imagen que mostraba a la pareja (Néstor y Cristina) Kirchner dándose un abrazo. En referencia al estilo gráfico peronista tradicional, posiblemente se intentó recrear un significante icónico similar al del histórico y emotivo abrazo entre Juan y Eva Perón, al declinar esta la candidatura a la vicepresidencia del país, en 1951. La leyenda elegida para el afiche fue: "Ahora más que nunca, habla Cristina".

Para comprender la eficacia simbólica del relato construido en torno a Néstor Kirchner y la visión del mundo que allí se propone, contemplamos algunas condiciones históricas de producción del mismo. Estas aparecen, mediadas por ciertas estrategias de modelización social y política, como huellas o marcas en el discurso. La narrativa del "Eternéstor" permite reconstruir retrospectivamente un pasado, ajustado a las necesidades del presente. Se procura legitimar o justificar las orientaciones ideológicas y políticas del líder en el presente político inmediato, ajustando o adaptando al mismo su trayectoria y la del movimiento político que condujo hasta su muerte.

Esta operación apela a sentidos construidos históricamente sobre el "debe ser" de la política (y, eventualmente, el "deber ser" del progresismo en política), que entran en correspondencia con los sentidos construidos alrededor de una serie de programas llevados adelante por los gobiernos de Néstor Kirchner (2003-2007) y de Cristina Fernández de Kirchner (2007 al presente). Por ejemplo, la ampliación de derechos de las minorías (como la ley de matrimonio igualitario), la ley de Servicios de Comunicación Audiovisual, un papel más activo del Estado en la economía, que incluyó medidas de nacionalización económica -estatización del sistema de jubilaciones y de la aerolínea de bandera-, la inversión en educación y obras públicas y "políticas de inclusión social" (subsidios a desocupados, asignación universal 
por hijo y jubilación a amas de casa). En buena medida, estas políticas -algunas de las cuales no fueron llevadas adelante por el Gobierno sino por el Congreso- fueron resultado de un ajuste de las disposiciones políticas del Gobierno a ciertas demandas sociales previas que el kirchnerismo ha sabido interpretar y capitalizar. Demandas y tendencias históricas que se inscriben no solo en la sociedad argentina, sino también en el contexto regional en el que el país se inserta. En ese sentido, ha existido desde fines de los años noventa hasta la actualidad, con matices y diferencias, un "giro" a la izquierda o a la centroizquierda en buena parte de los países de Sudamérica. Este "giro" se plasma en los cuestionamientos al modelo neoliberal y en la recuperación del Estado como protagonista del desarrollo económico y social de las naciones.

Respecto de El Eternauta, el kirchnerismo realiza una apropiación y reformulación de un lenguaje anterior, una cadena semiológica (Barthés, 1999), recurso que se remonta a la crisis del año 2001, cuando la imagen de El Eternauta con el rostro de Héctor Oesterheld -acompañada a veces de la leyenda "Resiste", en esténciles y pancartas, en calles y manifestaciones de Buenos Aires- es desarrollada y difundida por grupos de izquierda en los cuales militan, en su mayoría, jóvenes. Menos de una década después, la referencia a los usos callejeros de arte/política resulta deseable para un partido político que pretende una empatía y filiación de la juventud a sus filas. Allí observamos la transformación sobre la figura de Néstor Kirchner: esta referencia al mito del Oesterheld militante y desaparecido intenta establecer un paralelismo que permita extender estas características "guerreras" al pasado político del expresidente argentino. En el "Eternéstor", se reemplaza el rostro de Oesterheld, utilizado en los grafitos pos-2001, por el de Kirchner: antes de la muerte del expresidente, el mensaje se orienta a igualarlo como héroe de la resistencia al "invasor", a "los intereses monopólicos", "oligárquicos", "anti-populares", que es el constructo del antagonista ya mencionado en este artículo. Otro desplazamiento de sentido en el uso de la imagen de El Eternauta lo constituye la eliminación en los afiches oficiales, o bien el remplazo, de la escopeta original del personaje de la historieta (1957 1959), manteniendo el traje aislante de gutapercha que, en la segunda parte (1976-1978) es reemplazado por ropa de caza.

Sobre esta narrativa política, Reggiani (2011) considera que

... lo que está diciendo ese uso del símbolo, es que aún desde el Estado y aún después de muchos años de gobierno, el kirchnerismo o el peronismo piensa que es posible y deseable describir su acción como "resistencia [...] creo que si alguien tiene "derecho" a usar ese personaje, por tradición y por relaciones personales, es el kirchnerismo. Lo que más me interesaba es leer en la decisión de usar el personaje un modo de autocomprenderse por parte del kirchnerismo (s/n de pág.).

Luego de la muerte de Kirchner, su mitificación da un significativo paso, pues se suma un trágico factor común que sirve para canalizar la idea de sacrificio del héroe. Se da un proceso de re-significación de la imagen y de las ideas de resistencia y sacrificio desde El Eternauta, entregando(se) todo en la lucha contra los "Ellos"; pasando por Oesterheld, mitificado bajo un sacrificio real (fuese "voluntario" o no) como representante de un grupo de intelectuales militantes y desaparecidos durante la dictadura; hasta llegar a una construcción según la cual se sostiene que "Néstor Kirchner dio la vida por la patria" (Hebe de Bonafini, 23/03/201 1) o "Kirchner dio la vida por su país [...] se fue alguien indispensable" (Estela de Carlotto, 27/10/2010).

En un aspecto más amplio, esta mitificación fortalece una asociación entre el kirchnerismo y el peronismo de izquierdas de los años setenta, planteando al primero como el "recuperador", quien concreta el proyecto del segundo: es decir, la relación filial entre neovanguardia y vanguardia 
(Foster, 2001). Esta función restauradora (no en el sentido conservador del relato de la Cotidianeidad Positiva, como una "vuelta al orden original", sino entendido como una devolución de derechos, una respuesta concreta a demandas de organizaciones de derechos humanos como Madres y Abuelas de Plaza de Mayo y la asociación H. I. J. O. S., que durante años fueron postergadas por los gobiernos de turno) se enfatiza con las medidas gubernamentales relacionadas con la recuperación de la memoria reciente, llevadas a cabo desde 2003. Por otro lado, en materia económica, esta idea de restauración también alude a ciertas políticas de "nacionalización" económica -el sistema de jubilaciones, la aerolínea- y de recuperación del rol activo del Estado en la economía y en la regulación de relaciones sociales y laborales.

El "Eternéstor" es un tipo de construcción posdictatorial sobre los años setenta: (re) fundando este mito, el kirchnerismo se presenta como un articulador o bien un puente directo entre el proyecto del peronismo de izquierdas de los setenta ${ }^{4}$ y la "nueva militancia K".

\section{El mito, entre la mixtura estética y narrativa}

Como ya señaláramos, en la campaña comunicacional que comienza en setiembre de 2010 previo al acto político en el Luna Park- y que tiene un epicentro expresivo durante los días de los funerales de Kirchner y las semanas posteriores, se emplea un símbolo previamente mitificado, El

4 Durante la primera mitad de los años setenta, el movimiento peronista llegaba al final de su proscripción sin una estructura organizativa global, y a su interior existían sectores rivales: entre ellos, la "Tendencia Revolucionaria del Peronismo", compuesto principalmente por la Juventud Peronista y la organización político-militar Montoneros; este sector, denominado por diversas fuentes peronismo de izquierda, estaba enfrentado a la derecha peronista, sector "ortodoxo" conformado por la dirigencia partidaria tradicional, el peronismo sindical verticalista o "burocracia sindical" nucleado en la central obrera CGT, y una fracción disidente de la Juventud Peronista. Ambos sectores antagónicos lucharon por el poder suponiendo que "su" interpretación de las intenciones del conductor, Juan Perón, era la correcta. Dentro del imaginario del peronismo de izquierda de los setenta, la Juventud Peronista y el expresidente democrático Héctor Cámpora (1973) figuran entre sus referentes centrales.
Eternauta con el rostro del autor de la historieta, el cual (re)produce el mito del Oesterheld militante y desaparecido. Esta referencia a un mito anterior a partir de la reformulación del lenguaje del mismo procura establecer un paralelismo que extienda sus características combativas al pasado político de Kirchner, en concordancia con una mirada que asocia el personaje a un movimiento político y social que da sustento a su accionar: el peronismo de izquierda de los setenta, erigido en mito fundacional del peronismo en el poder desde 2003.

Este proceso sobre la figura de Néstor Kirchner que da origen a un nuevo relato y personaje, el "Eternéstor", incluye y combina otras manifestaciones provenientes de otros campos de la cultura e, incluso, de tradiciones políticas de otros países. Se han utilizado en la gráfica de las marchas y actos, frases como "mi único héroe en este lío" -que rima asonantemente con la de Oesterheld "el único héroe válido es el héroe colectivo" - y "vivir solo cuesta vida", fragmentos de letras de dos canciones del grupo argentino de rock Patricio Rey y sus Redonditos de Ricota , "Esa estrella era mi lujo" y "Ropa sucia", respectivamente. Esta inclusión de otro tipo de bienes culturales como la música -además de las frases y cánticos en clave de tribuna "futbolera" de homenaje a Kirchner, las expresiones políticas en la blogosfera y en las redes sociales digitales-, se combinan e interactúan con el uso del símbolo y el relato del "Eternéstor", como estrategias de mitificación del líder político.

Los sentidos e imágenes de esta narrativa forman un paisaje ideológico (Appadurai, 2001, p. 67) que incluye mesianismo y paternalismo, culto a la

5 Otro condimento legitimador de este uso de la letra de una canción de los Redonditos de Ricota en otro contexto de producción simbólica como lo es la comunicación política, fue la declaración a favor del Gobierno nacional producidas el 30 de noviembre de 2010 por el líder del actualmente disuelto grupo de rock, Carlos "Indio" Solari: "Soy básicamente de izquierda. No creo en las ideologías, sino en las personas que puedan llegar a ejecutar esas ideas. Me gusta ver una presidenta que hable de la manera que lo hace en la ONU, y por fin tenemos un gobierno con los cojones para enfrentar a todas las corporaciones al mismo tiempo" (Rolling Stone, http://www.rollingstone.com. ar/1329502). 
personalidad del líder (no solo de Kirchner sino también de la presidenta Cristina Fernández, considerada la "continuadora del modelo" o "proyecto"); apelación a la redención, al sacrificio patriota y militante, a la resistencia al enemigo poderoso, al "Ello" encarnado en la oposición política y en las "corporaciones", al sentimiento de desamparo y orfandad por la muerte del conductor. Asimismo, el relato del "Eternéstor" no solo (re)funda un mito conectándolo con el peronismo de izquierda de los setenta, sino que inscribe el liderazgo de Kirchner y de Cristina en una línea de continuidad con el peronismo histórico de los años cuarenta y cincuenta, encabezado por Perón y Evita ${ }^{6}$, con sus principios de justicia social, independencia económica y soberanía política, los cuales, a su vez, se interrelacionan con los contemporáneos de emancipación y unidad sudamericana ${ }^{7}$. Acude a una estrategia que no es nueva sino que es propia del peronismo: vincularse en un origen común con los desposeídos y los perseguidos, incluso posicionando al peronismo como fundacional en la historia argentina (Cataruzza, 2009).

Reproducimos abajo algunas de las frases que componen esta narrativa, especialmente entre los meses de septiembre y octubre de 2010, durante los cuales se producen la internación hospitalaria de Kirchner, el acto en el Luna Park con su presencia y la de Cristina Fernández de Kirchner (única oradora); y, luego, la muerte y los funerales del expresidente:

"No hay amor más grande que dar la vida por sus hermanos. Del dolor renace la fuerza y la esperanza. iFuerza, Cristina!".

6 Es notable la continuidad de sentidos que se genera entre varias frases de homenaje a Kirchner y la célebre frase de Eva Perón: "Volveré y seré millones".

7 Kirchner fue secretario general de la Unión de Naciones Sudamericanas (UNASUR) desde el 4 de mayo de 2010 hasta su muerte. Este organismo regional procura y alienta la integración de los países sudamericanos en diversos aspectos: dialogo político, integración física, energética y en materia de telecomunicaciones, la promoción de la inclusión y la justicia social, la defensa de la democracia en la región, el cuidado del medio ambiente, entre otros objetivos. Actualmente UNASUR está presidido pro tempore por Bharrat Jagdeo, jefe de Estado de Guyana.
Frase que se asemeja a las de las Madres y Abuelas de Plaza de Mayo, que promueven una construcción del héroe que se sacrifica por su pueblo: "Néstor Kirchner dio la vida por la patria" (Bonafini, 23/03/2011) "Kirchner dio la vida por su país[...] se fue alguien indispensable" (Carlotto, 27/10/2010).

Otros enunciados presentes en la gráfica y cánticos expuestos en la vía pública fueron:

"Millones de lágrimas censadas" ${ }^{8}$

"Que florezcan mil flores" 9

"Néstor no se murió, florece en nuestros corazones"

"No se murió, Néstor vive en el pueblo"

"iNéstor no se murió, Néstor no se murió, vive en los corazones de nuestro pueblo trabajador"

"Gracias, Néstor, por devolvernos la esperanza. Estarás eternamente en nuestros corazones".

"Porque el que murió peleando vive en cada compañero. Fuerza, Cristina"

"Fuerza, Cristina", "Fuerza Cristina, tu pueblo te necesita"

"Néstor con Perón, el Pueblo con Cristina"

"Eva, Perón y Néstor, juntos en el cielo. En la tierra, todos con Cristina"

"Néstor, mi bueno amigo, esta tarde volveremos a estar contigo..."

"No me importa lo que digan... los gorilas de Clarín"

8 "Millones de lágrimas censadas" fue una frase plasmada en carteles y graffitis callejeros, aparecida en Buenos Aires horas después de la muerte de Kirchner, y la entendemos como una sinécdoque que alude al hecho de que el deceso del ex presidente se produjo en el mismo día en que se estaba realizando el censo nacional de población.

9 La frase es del líder político chino Mao Zedong. Como ya expusiéramos, el kirchnerismo, en la construcción de su universo imaginario político, se nutre de fuentes que van más allá de su mito fundacional, el peronismo de izquierda de los setenta, y abreva en elementos del "peronismo histórico" y de otras tradiciones culturales y políticas. Es el caso de esta frase de Mao, en la cual encontramos cierta analogía con la frase atribuida a Eva Perón "volveré y seré millones". 
Y las ya mencionadas frases "ricoteras": "Mi único héroe en este lío" y "Fuerza compañero Néstor, sabemos que vivir solo cuesta vida".

En los días del velorio, fue colocada en la Pirámide de Mayo una gigantografía del personaje. "Bancando a Cristina" era la leyenda que estaba a los pies de la figura.

Como ya hemos señalado, la narrativa del "Eternéstor" continúa más allá de la muerte de Kirchner, y se ajusta a la estrategia oficialista de transmutar al líder en un símbolo de justicia social y de independencia frente a los poderes fácticos.

\section{Conclusiones}

Hemos analizado un caso en el cual la historieta es un elemento que vehiculiza estrategias políticas para imponer un discurso dentro del imaginario social, en este caso para naturalizar un mito construido. Esta mitificación resulta de un particular transcurso en los modos y medios en que ha sido instaurada. En los medios: las pancartas, esténciles, gráfica en general con la imagen de El Eternauta, que circularon en distintos soportes, tanto en papel en la vía pública como en el ágora digital formada por los nuevos medios de comunicación interactivos (Igarza, 2008): páginas web, weblogs y las redes sociales digitales; en estos espacios se generaron instancias de creación, socialización, intercambio de información e ideas y debate político, en las cuales la participación juvenil, aunque no exclusiva, fue significativa. En los modos: la estrategia surgida del fenómeno Néstor Kirchner muestra cierto margen de ludicidad e improvisación, sin estar fuertemente articulada al Gobierno, lo que también explica que el discurso oficial tardara un tiempo en apropiarse de la imagen mitificada.

Se opera una apropiación de la carga simbólica crítica de El Eternauta que trasciende la política estatal para vincularse con un discurso político partidario, especialmente de la rama juvenil del "kirchnerismo": La Cámpora. Existe, entonces, una finalidad diferente del uso de la imagen del Eternauta antes de la muerte de Néstor Kirchner y a posteriori, siendo en este último caso muy explícita la búsqueda de paralelismos con la idea de sacrificio heroico entre el personaje, el escritor y el político, en una operación empática hacia la joven militancia. Operación en la que resultó clave la hibridación de lenguajes y estéticas y la mediación de las nuevas tecnologías y los nuevos medios en la creación, circulación y recepción de mensajes políticos. Estos, en ciertos casos, tuvieron una función instrumental más allá de la simbólico-expresiva: las convocatorias vía web a diversas acciones y eventos políticos, sociales y culturales, por ejemplo, implica una apuesta de construcción de tejido social. Asimismo, esta nueva narrativa mítico-heroica sobre el líder ha abierto un nuevo espacio de posibilidades de recepción de la historieta El Eternauta, en tanto que el "Eternéstor" se constituye "como otra manifestación de esas relecturas contextualizadas en tiempo y lugar" (Chinelli, 2010).

Lo destacable de este caso es no solo observar cómo la historieta sigue reinventándose como herramienta del discurso social y político, sino también cómo su historia y sus personajes ya forman parte del universo simbólico argentino y sudamericano.

\section{Referencias bibliográficas}

Appadurai, A. (2001). La modernidad desbordada. Dimensiones culturales de la globalización. $1^{a}$ traducción al español. Buenos Aires: Fondo de Cultura Económica.

Barthes, R. (1999). Mitologías. $12^{\circ}$ Edición. México D.F.: Siglo Veintiuno.

Bourdieu, P. (1987). Cosas Dichas. Barcelona: Gedisa Editorial.

Bourdieu, P. (1990). Sociología y cultura. México D.F.: Grijalbo. 
Bourdieu, P. (1995). Las Reglas del Arte: Génesis y estructura del campo literario. Barcelona: Anagrama.

Cataruzza, A. (2009). Historia de la Argentina (19161955). Buenos Aires: Siglo Veintiuno.

Chartier, R. (2002). El mundo como representación. Barcelona: Gedisa.

Foster, H. (2001). El retorno de lo real. La vanguardia a finales de siglo. $1^{\circ} \mathrm{Ed}$. en español $\left(1^{\circ} \mathrm{Ed}\right.$. en inglés: 1996). Madrid: Akal.

Igarza, R. (2008). Nuevos medios. Estrategias de convergencia 3.0. Buenos Aires: La Crujía Ediciones.

Jitrik, N. (1995). Historia e imaginación literaria. Las posibilidades de un género. Buenos Aires: Biblos.

Reggiani, F. (2011). Las aventuras de Nestornauta. Recuperado el día 25 de febrero de 2011, del blog Hablando del asunto. (Citamos un comentario del autor del post). Disponible en: http://hablandodelasunto.com. $\operatorname{ar} / \mathrm{p}=8635$

Ricoeur, P. (2005). Sobre la traducción. Buenos Aires: Paidós.

Richard, N. (2007). Fracturas de la memoria. Arte y pensamiento crítico. Buenos Aires: Siglo Veintiuno.

Roig, A. (1984). Narrativa y Cotidianidad. La obra de Vladimir Propp a la luz de un cuento ecuatoriano.

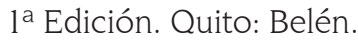

Sánchez Ruiz, E. (2007) El regreso de la "ideología" en la investigación de la comunicación: mitos y realidades sobre la globalización, la integración y las identidades. En D. Loreti y otros (comp.). Participación y democracia en la sociedad de la información (pp. 71-90) Buenos Aires, Argentina: Prometeo Libros.

Sánchez, A. y Olivares, D. (2010) "Mitos peronistas en el discurso de Cristina Fernández de Kirchner". Ponencia presentada en el Congreso 200 años: Medios, Comunicación y Cultura, organizado por la Escuela de Ciencias de la Información, UNC, setiembre de 2010. Córdoba.

Sigal, S. y Verón, E. (2008). Perón o muerte. Los fundamentos discursivos del fenómeno peronista. $2^{\circ}$ Ed. Buenos Aires: Eudeba.

Van Dijk, T. (1995). Discourse semantics and ideology. En Van Dijk (Ed.). Discourse E Society (243-289). Londres: Sage Publications.

Verón, E. (1993). La semiosis social. Barcelona: Gedisa Editorial.

von Sprecher, R. (2006). Recepción y consumo de medios masivos de comunicación y de nuevas tecnologías de la información y la comunicación, en la ciudad de La Rioja (República Argentina). Tesis doctoral. Tenerife: Universidad de La Laguna.

\section{Blogs, sitios web, periódicos}

Archivo Histórico Héctor Germán Oesterheld, administrado por Mariano Chinelli. http://archivohgo. blogspot.com/

Revista Rolling Stone

http://www.rollingstone.com.ar/1329502 
